\title{
Model-Based Control of an Integrated Fuel Cell and Fuel Processor With Exhaust Heat Recirculation
}

\author{
Vasilis Tsourapas, Student Member, IEEE, Anna G. Stefanopoulou, Senior Member, IEEE, and \\ Jing Sun, Fellow, IEEE
}

\begin{abstract}
In this paper, we consider the dynamic and controlled operation of an integrated natural gas fuel processor system (FPS), a proton exchange membrane fuel cell (PEM-FC), and a catalytic burner (CB). The FC provides power based on the electrochemical reaction of hydrogen. The FPS generates the hydrogen from natural gas through catalytic partial oxidation (CPOX) and the CB provides the energy for preheating the FPS inlet flows by burning any excess hydrogen from the FC exhaust. The coupling of these three systems poses a challenging optimization and control problem. Optimization is performed to generate the air and fuel flow intake setpoints to the FPS for various load levels. The optimal flow setpoints are used in a static feedforward map that ensures maximum efficiency at steady state. Linear quadratic techniques are then used to develop a controller to mitigate hydrogen starvation in the fuel cell and regulate CPOX reactor temperatures. We show in simulations that the designed observer-based feedback controller, which relies on temperature measurements of two reactors, speeds up the transient response fourfold, as compared to the baseline when the static feedforward controller is employed.
\end{abstract}

Index Terms-Dynamics, feedback control, fuel cells (FCs), fuel processor, modeling.

\section{INTRODUCTION}

$\mathbf{F}$ UEL CELL (FC)-based power plants, given their high efficiency and clean exhaust, represent a great opportunity in addressing energy and environmental issues. Proton exchange membrane fuel cells (PEM-FCs) operate at low temperature $\left(<90^{\circ} \mathrm{C}\right)$ and allow easier start-up and manufacturing processes than other FC types. Due to the low temperature, however, PEM-FCs require reforming hydrocarbon fuels to gas rich in hydrogen. In this paper, we consider a natural gas fuel processor based on a catalytic partial oxidation (CPOX) reactor [1]. The fuel processor is then responsible for supplying hydrogen to the FC stack to support the electrochemical reactions associated with the current drawn from the FC stack. Typically, excess hydrogen is necessary to: 1) avoid lack of

Manuscript received August 16, 2005. Manuscript received in final form August 22, 2006. Recommended by Associate Editor J. Lee. This work was supported in part by the National Science Foundation under Contracts NSF-CMS0201332 and NSF-ECS-0501284, by the Automotive Research Center under U.S. Army Contract DAAE07-98-3-0022, and by the Department of Defense under U.S. Navy Contract N00014-05-1-0044.

V. Tsourapas and J. Sun are with the Department of Naval Architecture and Marine Engineering, University of Michigan, Ann Arbor, MI 48109-2145 USA (e-mail: djvas@umich.edu; jingsun@umich.edu).

A. Stefanopoulou is with the Department of Mechanical Engineering, University of Michigan, Ann Arbor, MI 48109-2121 USA (e-mail: annastef@umich. edu).

Color versions of Figs. 1-12, 14, and 15 are available at http://ieeexplore. ieee.org.

Digital Object Identifier 10.1109/TCST.2006.886431

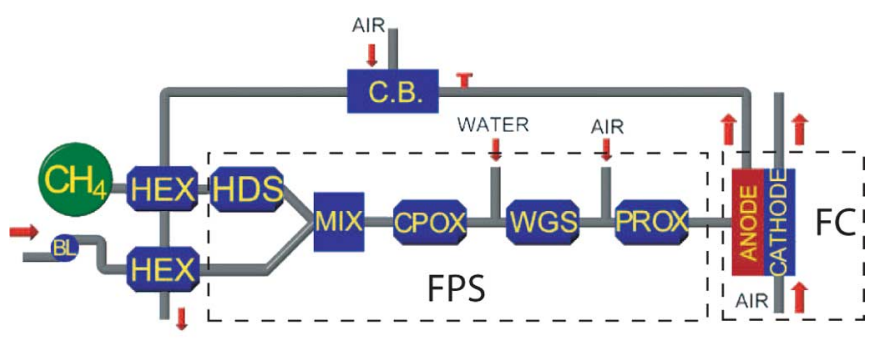

(a)

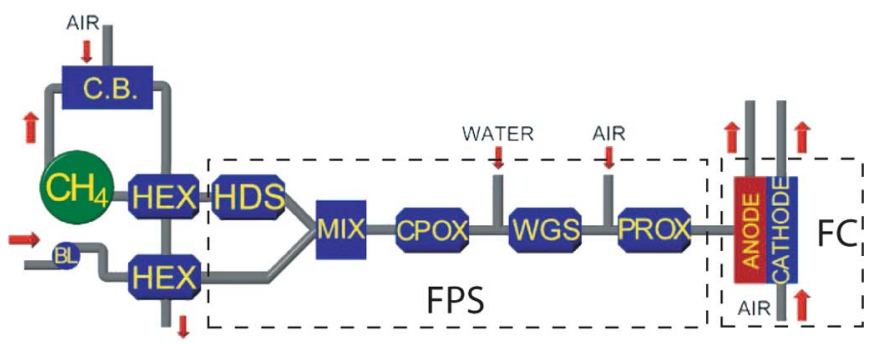

(b)

Fig. 1. (a) IHPS and (b) EHPS.

hydrogen, also known as hydrogen starvation, at the last cell in the FC stack and 2) allow the FC to operate at higher hydrogen concentration, and thus, higher stack efficiency. Operating with excess hydrogen also provides a buffer during fast load changes. Therefore, excess hydrogen supply might be beneficial for the FC, but decreases the overall system (FPS + FC) efficiency and requires safe discharge measures, such as adequate ventilation or burning of anode exhaust gas.

One way to eliminate the excess hydrogen that does not participate in the electrochemical reactions and, at the same time, increase the system efficiency is to use it in a reactor after it exits the FC anode exhaust. Specifically, a catalytic burner (CB) can harvest energy from the excess hydrogen via oxidation with air. This energy can be then used to preheat the FPS inlet flows. For steady-state operation, as much as $16 \%$ efficiency improvement can be achieved when the excess hydrogen in the FC exhaust is burnt in a CB instead of burning a dedicated and separate stream of natural gas in a CB (as shown in the two schematics in Fig. 1) to provide energy for preheating the inlet fuel and air streams to the FPS [2].

In this paper, we consider the exhaust heat recirculation power system, referred to as internally heated power system (IHPS) [Fig. (1a)], which results from the integration of a FC stack that generates electric power, an FPS that produces a hydrogen rich mixture to be fed to the fuel cell, and a CB that recuperates any excess hydrogen leaving the $\mathrm{FC}$ to provide 


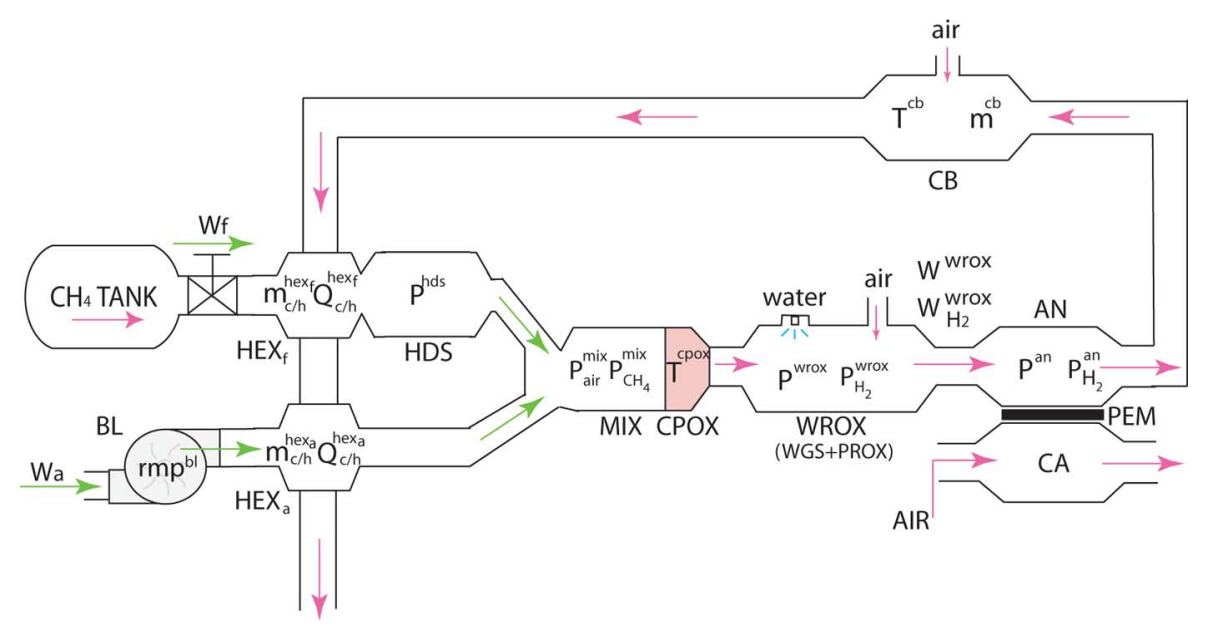

Fig. 2. IHPS model state variables.

preheating energy. The closely coupled dynamics of the three subsystems, together with the large thermal inertia and, therefore, slow transients associated with the fuel processor, impose a very challenging control problem. The externally heated power system (EHPS) is also shown in Fig. 1(b).

In order to achieve maximum overall efficiency, the integrated IHPS has to work very close to its operating boundary as shown later in this paper. This optimal set-point selection, however, puts the system in a very vulnerable position during load $^{1}$ transitions. When the load is suddenly increased, the IHPS may not be able to provide sufficient $\mathrm{H}_{2}$ and heat to sustain the operation under the new load condition. This can lead to temporary $\mathrm{H}_{2}$ starvation, thereby causing irreversible damage to the FC. To avoid the $\mathrm{H}_{2}$ starvation, we simply require that the $\mathrm{H}_{2}$ produced from the FPS is higher than the hydrogen required for the electrochemical reactions in the FC. Transient issues associated with temporary hydrogen starvation can be avoided by slowing down the current drawn from the fuel cell through a rate limiter or a load governor [3]. The power deficit, in this case, can be provided through hybridization [4], with an additional electrical power source which will increase cost and system complexity. Another typical approach that does not rely on hybridization is to have the FPS produce excess hydrogen than that required. However, this will lower the FC utilization and, in turn, the IHPS efficiency.

Operating at optimal steady state and, thus, capitalizing the benefits of the IHPS will be made possible only if the controlled system responds to FC load changes very fast. Otherwise, one has to resort to suboptimal setpoints, i.e., to trade efficiency for improved safety margin. In this paper, we design a controller that is aimed at speeding up the natural IHPS dynamics while maintaining optimum reactor temperatures and overall system efficiency. The feedback controller is based on measuring reactor temperatures and estimating the spatially averaged composition of reactant flow through the series of IHPS components. An earlier conference paper [5] reports the initial results on control design. This paper provides more in depth analysis of the controlled system.

${ }^{1}$ In this paper, the term "load" is synonymous to the current drawn from the fuel cell.

\section{OVERVIEW OF THE IHPS OPERATION AND ITS DYNAMIC MODEL}

The IHPS investigated in this paper, shown in Fig. 1(a), is composed of five main reactors, namely, the hydro-desulfurizer (HDS), the CPOX, the water gas shift (WGS), the preferential oxidizer (PROX) and the CB. The first four reactors comprise the FPS. The intended application for the IHPS is the generation of power in a commercial building so natural gas is the targeted fuel. Natural gas contains on average $95 \%$ of methane $\left(\mathrm{CH}_{4}\right)$, we thus assume that pure methane is supplied to the FPS to be reformed into a rich $\mathrm{H}_{2}$ flow. A 200-kW PEM-FC uses the $\mathrm{H}_{2}$ in the reformed flow to generate electric power. All FPS and FC components operate at low pressures of up to $130 \mathrm{kPa}$.

A 19-state nonlinear, control-oriented, dynamic model of the IHPS is developed in order to analyze its behavior [2], [5]. The dynamic states of the model are indicated inside the volumes in Fig. 2 while other important variables are also shown such as the mass flow rates $W_{f}, W_{a}, W^{\text {wrox }}$, and $W_{\mathrm{H}_{2}}^{\mathrm{wrox}}$ (see nomenclature definitions in the Appendix). In [6], the initial model of the fuel processor was developed. The model in [6] assumed constant inlet temperature and did not include the heat exchangers and the CB.

Some important assumptions about the developed model are that all gases obey the ideal gas law and that each reactor is modeled as a lumped parameter volume with homogenous pressure and temperature distribution. The model is not suitable for start up or shut down simulations because chemical kinetics for the ignition/extinction dynamics have not been modeled. Finally, the model is valid for the range of FC loads between $20 \%$ to $80 \%$ (i.e., $50-160 \mathrm{~kW}$ or $70-250 \mathrm{~A}$ ). Within this range of loads, the FC stack voltage varies between 0.71 and $0.64 \mathrm{~V}$ per cell with a total of 1000 cells of $0.04 \mathrm{~m}^{2}$ active area [7].

A brief description of the system operation is given in the following paragraphs with the governing dynamic equations summarized in Table II located in the appendix. The calculations for the chemical reactions in the CPOX and more details on the modeling can be found in [2], [5], and [7].

The fuel (i.e., methane) flow into the system is defined based on the valve command $u_{f}$ and (A32) from the appendix. The main air flow is supplied to the system by a blower (BL) 

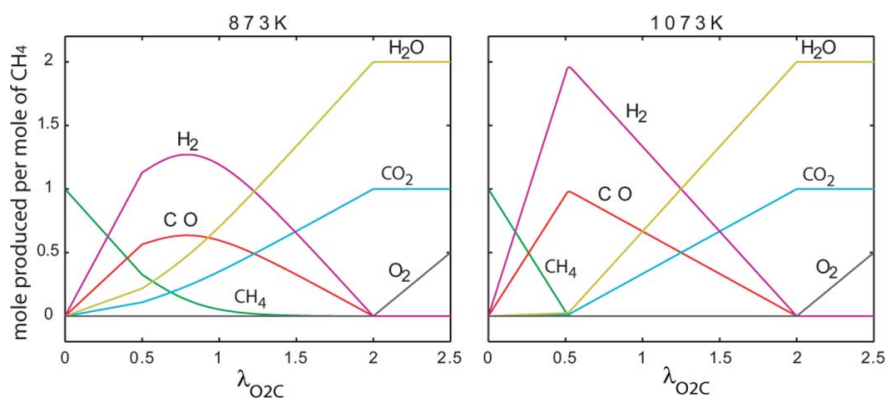

Fig. 3. CPOX products as a function of $\lambda_{\mathrm{O} 2 \mathrm{C}}$ and reactor temperature.

which draws humidified air. The blower speed in revolutions per minute $(\mathrm{r} / \mathrm{min})$ is calculated via (A31) as a function of the air command $u_{a}$. Using the calculated blower speed and the blower map, the air flow is determined. The air and the fuel are preheated in separate heat exchangers (HEX). The HDS is used to remove the sulfur from the fuel flow [8], [9]. In this paper, only pressure dynamics are considered in the HDS (A36). The dynamic states in the HEX include mass (A33) and heat (A34). Then, the two flows are mixed in the mixer (MIX) where the partial pressure dynamics of the $\mathrm{CH}_{4}$ (A37) and the air (A38) are taken into account. A static mixing relationship (A39) of the two flows is used to calculate the temperature of the MIX flow. The mixture is then passed through the catalytic partial oxidizer (CPOX) where $\mathrm{CH}_{4}$ reacts with oxygen to produce $\mathrm{H}_{2}$. There are two main exothermal chemical reactions taking place in the CPOX: partial oxidation (POX) and total oxidation (TOX) given in [10] and [11] with their corresponding energy release per mole of reactant $\left(\Delta H^{0}\right)$

$$
\begin{array}{cc}
\text { (POX) } & \mathrm{CH}_{4}+\frac{1}{2} \mathrm{O}_{2} \rightarrow \mathrm{CO}+2 \mathrm{H}_{2} \\
\Delta H_{\mathrm{pox}}^{0} & =-0.036 \times 10^{6} \mathrm{~J} / \mathrm{mol} \\
(\mathrm{TOX}) & \mathrm{CH}_{4}+2 \mathrm{O}_{2} \rightarrow \mathrm{CO}_{2}+2 \mathrm{H}_{2} \mathrm{O} \\
\Delta H_{\text {tox }}^{0} & =-0.8026 \times 10^{6} \mathrm{~J} / \mathrm{mol} .
\end{array}
$$

Hydrogen is produced only by the POX reaction while heat is mostly generated by the TOX reaction. As shown in Fig. 3, the distribution between the two is dictated by the reactor temperature $T^{\mathrm{cpox}}(\mathrm{A} 40)$ and the molar flow ratio of oxygen $\left(\mathrm{O}_{2}\right)$ in the air to $\mathrm{CH}_{4}$ in the MIX defined as

$$
\lambda_{\mathrm{O} 2 \mathrm{C}}=\dot{n}_{\mathrm{O}_{2}} / \dot{n}_{\mathrm{CH}_{4}} .
$$

Moreover, since the CPOX products are also highly dependent on the CPOX reactor temperature $T^{\mathrm{cpox}}$, the optimum balance between the two reactions has to be determined.

Carbon monoxide (CO) is created along with $\mathrm{H}_{2}$ in the POX reaction, as can be shown in (1). Since CO poisons the PEM fuel cell catalyst, it has to be eliminated using water in the WGS reactor and air in the PROX. The latter are assumed to operate perfectly, thus, eliminating all the $\mathrm{CO}$ in the stream. In the model, the PROX and WGS reactors are merged in one volume called the WROX, where the total pressure dynamics (A41) and the $\mathrm{H}_{2}$ partial pressure dynamics (A42) are included. Note that it might be necessary to include additional heat exchangers among the WGS, PROX reactors, and the FC to achieve the optimum inlet temperature for each reactor. These heat exchangers are neglected here by assuming, for example, that the water sprayed in the WGS offers the appropriate cooling of the flow streams [12].

The $\mathrm{H}_{2}$-rich mixture leaving the WROX enters the anode of the fuel cell stack where the electro-chemical reaction takes place to convert $\mathrm{H}_{2}$ to electrical power. The anode model includes the total pressure and the $\mathrm{H}_{2}$ partial pressure dynamics, specified in (A43) and (A44), respectively. The reacting $\mathrm{H}_{2}$ is given as a function of the demanded load (A45) and the resulting voltage as a function of $\mathrm{H}_{2}$ pressure and the demanded load (A46). The flow from the anode is then supplied to the CB where the excess $\mathrm{H}_{2}$ is burnt using the air supplied through a blower. The temperature dynamics in the $\mathrm{CB}$ are given in (A49), where the heat released from burning the $\mathrm{H}_{2}$ is a function of the air-to- $\mathrm{H}_{2}$ stoichiometry in the $\mathrm{CB}$ (A51). Finally, the flow from the CB is fed to two separate heat exchangers (HEX-hot side), one to preheat the air and one to preheat the fuel flows before they enter the FPS. The utilization of this heat results in increased overall efficiency of the system. The model without the $\mathrm{CB}$ has been verified with a higher order model [7], while the $\mathrm{CB}$ model trends and qualitative response have also been verified [13].

A similar FPS configuration is studied in [14], where a dynamic model of the system suitable for observer design and start up analysis is presented. Sommer in [15] develops a dynamic model of an autothermal reformer. The effects of volume sizes on the system's transient performance, as well as the benefit of the heat capacity of each volume that acts as a buffer during transients are analyzed. The need for precise inlet flow control can also be inferred. An explicit dynamic model for direct reforming carbonate fuel cell stack is developed in [16]. Using thermodynamic principles and mass/energy conservation, the authors of [16] develop a 10-state model suitable for transient analysis and validate it with a higher order model and experimental results. During transient operation temperature overshoot problems are observed, similarly to our analysis. The authors of [17] develop a model to study the performance on a steam reformer and a PEM FC-based system. Using a simple rate limiter control of the input flows they also note the possibility of overheating the catalyst bed. In [18], a molten carbonate dynamic model is developed and the authors note the coupling between the load following capabilities and the input flow scheduling during a transient as well as the temperature and $\mathrm{H}_{2}$ production fluctuations. In [19], after using a dynamic model to examine the transient system behavior of a 1-mW FC power plant, the authors reach the conclusion that feedback control is required to enhance the load following capabilities of the system. Finally, similar studies using dynamic FPS-FC models can also be found in [20]-[23].

All dynamic studies of IHPS mentioned in this literature review concur, explicitly or implicity, to the need of feedback control of the inlet air and fuel flows to the system. Several authors also mention that feedforward scheduling of those flows is inadequate in order for the system to meet the load following requirements, a conclusion that will be supported by the open loop analysis in this paper (Section IV). 


\section{STEADY-STATE EFFICIENCY OPTIMIZATION}

For the system to work efficiently in an integrated fashion, each component has to be conditioned properly in terms of its operating temperature, humidity, and pressure. This is achieved by controlling the air and fuel intakes of the FPS. The strong physical coupling of the IHPS components will dictate the optimal set-points for the system.

To determine the optimal steady-state operating points with respect to the overall system efficiency, the following optimization problem is formulated:

$$
\max _{\left(u_{f}, u_{a}\right)}\left(\eta_{\mathrm{IHPS}}=\frac{V \cdot I_{\mathrm{st}}}{W_{f} \cdot Q_{\mathrm{LHV}}^{\mathrm{CH}_{4}}}\right) .
$$

The objective is to maximize the overall efficiency $\eta_{\text {IHPS }}$, which is defined as the ratio of the FC electric power output $V \cdot I_{\text {st }}$ over the energy used $W_{f} \cdot Q_{\mathrm{LHV}}^{\mathrm{CH}_{4}}$, where $W_{f}$ is the amount of fuel used and $Q_{\mathrm{LHV}}^{\mathrm{CH}_{4}}$ its lower heating value. The optimization variables are the fuel valve command $u_{f}$ and the air blower command $u_{a}$, both ranging from $0 \%$ to $100 \%$, corresponding to fully closed or fully open actuators, respectively.

The gradient method is employed to solve the optimization problem [24]. The corresponding iterative algorithm is given as

$$
u_{k+1}=a_{k} \cdot \nabla \eta_{\mathrm{IHPS}}^{T}+u_{k}
$$

where $a_{k}$ is the iteration step, $\nabla \eta_{\text {IHPS }}^{T}\left(u_{k}\right)$ is the gradient vector which corresponds to the $\eta_{\text {IHPS }}$ increasing direction and $u=$ $\left[\begin{array}{ll}u_{f} & u_{a}\end{array}\right]^{T}$. The iteration step size $a_{k}$ is kept constant until no new direction can be found for $\eta_{\text {IHPS }}$ to increase, and $a_{k}$ is then reduced by the bisection method up to the desired accuracy.

Convergence of the gradient algorithm to a global maximum can be verified given the convex form of the efficiency map for the whole range of FC loads. An example of the efficiency map is given in Fig. 4 for the FC load of $100 \mathrm{~A}$. The maximum efficiency for this load is $33.6 \%$ while the optimal setpoint is $\left[\begin{array}{ll}u_{f}^{*} & u_{a}^{*}\end{array}\right]=\left[\begin{array}{ll}20.75 & 29.00\end{array}\right]$.

Using the same procedure for each operating load, the optimal steady-state setpoint map can be determined for the actuator inputs $u_{I_{\mathrm{st}}}^{*}=\left[\begin{array}{ll}u_{f}^{*} & u_{a}^{*}\end{array}\right]^{T}$ and other critical operating variables (for example, $T_{I_{\mathrm{st}}}^{\mathrm{cpox} *}$ ) that can serve later as controller setpoints. The optimization results are shown in Fig. 5 and can be approximated by the regression expressions

$$
\begin{aligned}
u_{f}^{*}= & 7 \cdot 10^{-7} I_{\mathrm{st}}^{4}-0.0003 I_{\mathrm{st}}^{3}+0.0637 I_{\mathrm{st}}^{2} \\
& -4.9581 I_{\mathrm{st}}+149.12 \\
u_{a}^{*}= & 0.3135 I_{\mathrm{st}}-2.3897 \\
W_{f}^{*}= & 5 \cdot 10^{-5} I_{\mathrm{st}}-0.0005 \\
W_{a}^{*}= & 0.0003 \cdot I_{\mathrm{st}}-0.0023
\end{aligned}
$$

where $W_{f}$ and $W_{a}$ are the corresponding optimal flows in $(\mathrm{kg} / \mathrm{s})$ of air and fuel when using $u_{f}^{*}$ and $u_{a}^{*}$. These four curve fits for the optimal setpoints are valid for the range of FC loads between $20 \%$ and $80 \%$.

As illustrated in Fig. 4, the optimal operating setpoint lies close to the operating boundary of the system, where the operating boundary is defined as the locus of points where $\eta_{\mathrm{IHPS}}=$

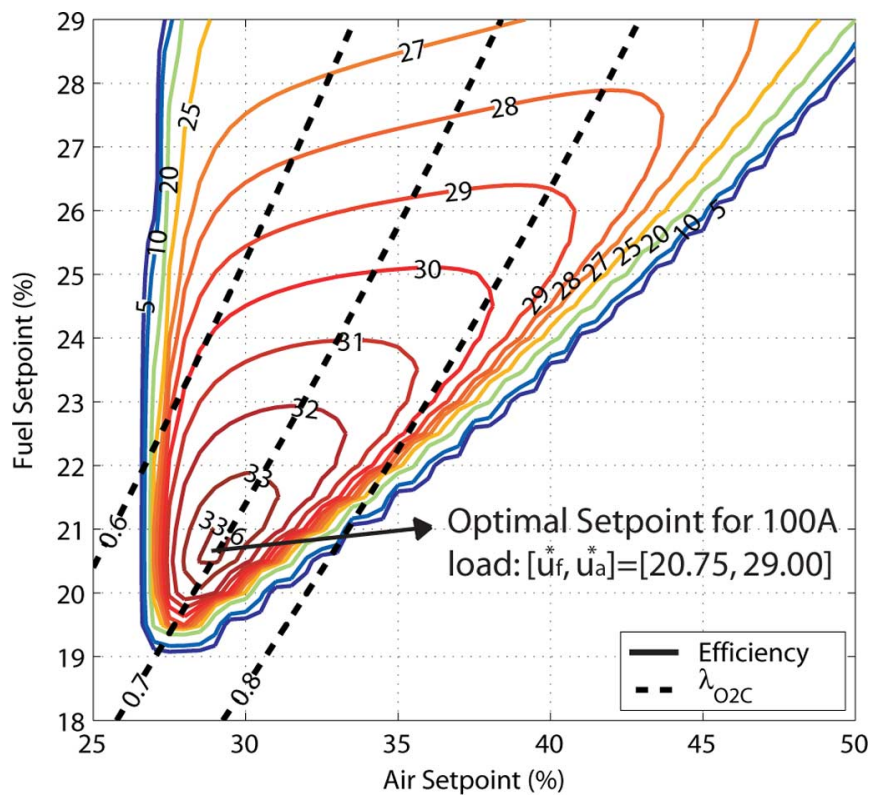

Fig. 4. Efficiency map of the IHPS at load $I_{\mathrm{st}}=100 \mathrm{~A}$ (numbers on the contours indicate corresponding efficiency).
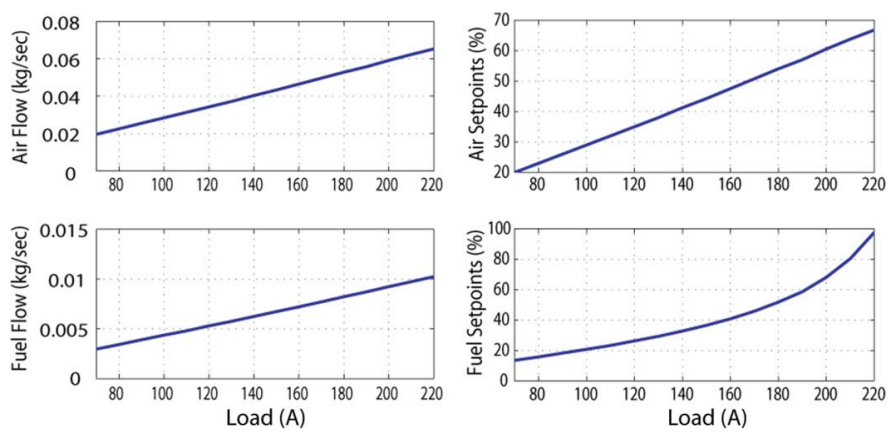

Fig. 5. Optimal air and fuel flows and setpoints versus FC load.

$0 \%$. Outside this boundary the produced $\mathrm{H}_{2}$ is less than that required by the FC. This trend is observed for the whole range of operating loads of the system. As a result, the system is susceptible to steady-state $\mathrm{H}_{2}$ starvation when there are uncompensated loads during steady-state and transient operation. To avoid modeling errors and to react fast to load variations, a combination of feedforward and feedback control is designed.

It is important to point out that according to the optimization results, all the optimal operating points, independent of the load applied to the $\mathrm{FC}$, occur at $\lambda_{\mathrm{O} 2 \mathrm{C}}^{*}=0.69$ and $T^{\mathrm{cpox} *}=980 \mathrm{~K}$. Note that the optimization of the overall IHPS efficiency (4) leads to a CPOX oxygen to carbon ratio $\left(\lambda_{\mathrm{O} 2 \mathrm{C}}^{*}\right)$ that is greater than the value corresponding to the maximum $\mathrm{H}_{2}$ production for the CPOX reactor $\left(\lambda_{\mathrm{O} 2 \mathrm{C}}=0.5\right.$ as indicated in Fig. 3$)$.

In order to explain this result, one has to notice that while both POX and TOX reactions in (1) and (2) are exothermal, the TOX releases 20 times more heat than the POX reaction. The CPOX temperature, which is highly coupled to the $\mathrm{H}_{2}$ production in the case of the integrated IHPS, is a function of both the heat released by the reactions inside the CPOX and the temperature of the incoming air and fuel flows. Moving $\lambda_{\mathrm{O} 2 \mathrm{C}}$ towards 0.5 will promote $\mathrm{H}_{2}$ production but suppress the TOX reaction 


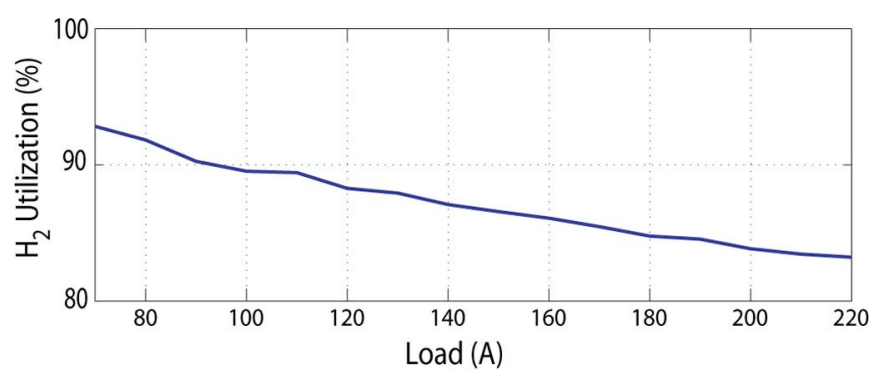

Fig. 6. $\mathrm{H}_{2}$ utilization versus FC load.

which only occurs for $\lambda_{\mathrm{O} 2 \mathrm{C}}>0.5$. Thus, the contribution of the TOX reaction to the CPOX temperature will be reduced and, as a result, the CPOX reactor has to rely on preheating the inlet flows by the CB. Since both variables (the $\mathrm{H}_{2}$ and heat) are essential for the system to function properly, the optimal point $\left(\lambda_{\mathrm{O} 2 \mathrm{C}}^{*}=0.69\right)$ reflects a balance between the $\mathrm{H}_{2}$ production in the FPS and heat generation in the CB and the CPOX reactors for steady-state operation. Thus, the overall IHPS optimum cannot be defined through optimization of individual components.

Another interesting optimization result is the $\mathrm{H}_{2}$ utilization $\left(U_{\mathrm{H}_{2}}\right)$ in the FC shown in Fig. 6 and defined as

$$
U_{\mathrm{H}_{2}}=\frac{\mathrm{H}_{2} \text { reacted }}{\mathrm{H}_{2} \text { supplied }}=\frac{W_{\mathrm{H}_{2}}^{\text {react }}}{W_{\mathrm{H}_{2}}^{\text {wrox }}}
$$

where $W_{\mathrm{H}_{2}}^{\text {wrox }}$ is the amount of hydrogen supplied to the $\mathrm{FC}$ (i.e., exiting the WROX) and $W_{\mathrm{H}_{2}}^{\text {react }}$ is the amount of $\mathrm{H}_{2}$ consumed in the $\mathrm{FC}$ at a given load. The need for decreasing the $\mathrm{H}_{2}$ utilization as load increases is dictated not only by the need for excess $\mathrm{H}_{2}$ for preheating as load increases, but also by the fuel cell efficiency. At higher loads, excess $\mathrm{H}_{2}$ promotes the fuel cell efficiency and, in turn, the overall system efficiency of the IHPS. Indeed, the $\mathrm{H}_{2}$ utilization in both the IHPS [Fig. 1(a)] and the EHPS [Fig. 1(b)] are found to be equal after dedicated EHPS optimization was performed. Thus, the need for decreasing the utilization at high loads is mostly due to the requirement for high FC efficiency (37\% at max load). This is the case for both IHPS and EHPS, independent of the $\mathrm{H}_{2}$ recirculation loop.

The IHPS will exhibit higher efficiency and lower fuel consumption when compared against the EHPS as shown in Fig. 7. Note that the efficiency shown in Fig. 7 is the FPS efficiency defined as

$$
\eta_{\mathrm{FPS}}=\frac{W_{\mathrm{H}_{2}}^{\mathrm{wrox}} \cdot Q_{\mathrm{LHV}}^{\mathrm{H}_{2}}}{W_{f} \cdot Q_{\mathrm{LHV}}^{\mathrm{CH}_{4}}} .
$$

At high loads, an efficiency increase of up to $12 \%$ and a fuel consumption decrease of up to $16 \%$ can be achieved. Thus, the addition of a hydrogen recirculation $\mathrm{CB}$ is quite beneficial for such a fuel processing unit.

\section{OPEn-LoOp DynAmic ANALYSIS}

Examining the transient performance of the system using static feedforward control enables us to gain insight on the

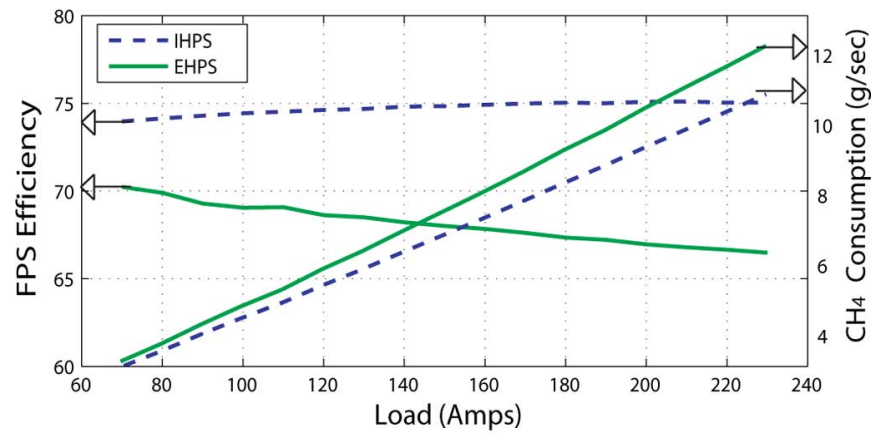

Fig. 7. Efficiency and fuel consumption of IHPS and EHPS.

system dynamics. The open-loop system dynamics are examined by utilizing the optimal steady-state setpoint maps derived from the optimization results, where for a given load, the fuel and air operating setpoint are defined by the feedforward maps (6) and (7).

The open-loop response of the system for two consecutive load steps is shown in Fig. 8. For the initial small step of 90-100 A, the fuel processor provides the fuel cell with the required amount of $\mathrm{H}_{2}$ in order to meet the load demand. For the second larger step of 100-150 A though, the $\mathrm{H}_{2}$ generation is below the demanded $\mathrm{H}_{2}$ level for a considerable period of $7 \mathrm{~s}$. Starving the fuel cell for $7 \mathrm{~s}$ can cause power loss and membrane damage while it jeopardizes the life span of the stack [25]. Moreover, a $65^{\circ}$ overshoot in the CPOX temperature within $15 \mathrm{~s}$ is observed, which can have damaging consequences for the CPOX reactor. Both issues are highlighted on Fig. 8. Since the feedforward maps correspond to maximum efficiency steady-state operation, it is not surprising that the open-loop control is inadequate in preventing $\mathrm{H}_{2}$ starvation when a large load step is applied.

In order to identify the root cause of the $\mathrm{H}_{2}$ starvation and temperature overshoot of the IHPS, we consider three critical processes that affect the generation of $\mathrm{H}_{2}$ during load changes. Analyzing those processes will provide insight in the control problem and the system design. The first critical process is found to be the CB temperature variation during a step change in load. When a step load is applied, the $\mathrm{H}_{2}$ flow is depleted at a rate faster than it is produced, due to the slow time constant of the FPS. This results in reduction or even elimination of the $\mathrm{H}_{2}$ flow to the $\mathrm{CB}$, which, in turn, results in a temperature reduction in the $\mathrm{CB}$ and eventually a temperature reduction of the inlet air and fuel flows. However, the thermal inertia and relatively large time constant of the $\mathrm{CB}$ prevents the temperature from dropping quickly, therefore, helping to maintain the temperature at a level that does not affect the $\mathrm{H}_{2}$ production. A comparison of the IHPS, where the CB temperature is a function of the $\mathrm{H}_{2}$ present in the anode exhaust, with an imaginary system where the $\mathrm{CB}$ temperature is maintained constant at a nominal value, is given in Fig. 9(a) and (b). The two responses are almost identical, with the constant CB temperature response [Fig. 9(b)] exhibiting slightly less $\mathrm{H}_{2}$ starvation. Consequently, the CB temperature variation during load increase is not the main cause of the $\mathrm{H}_{2}$ starvation problem. 

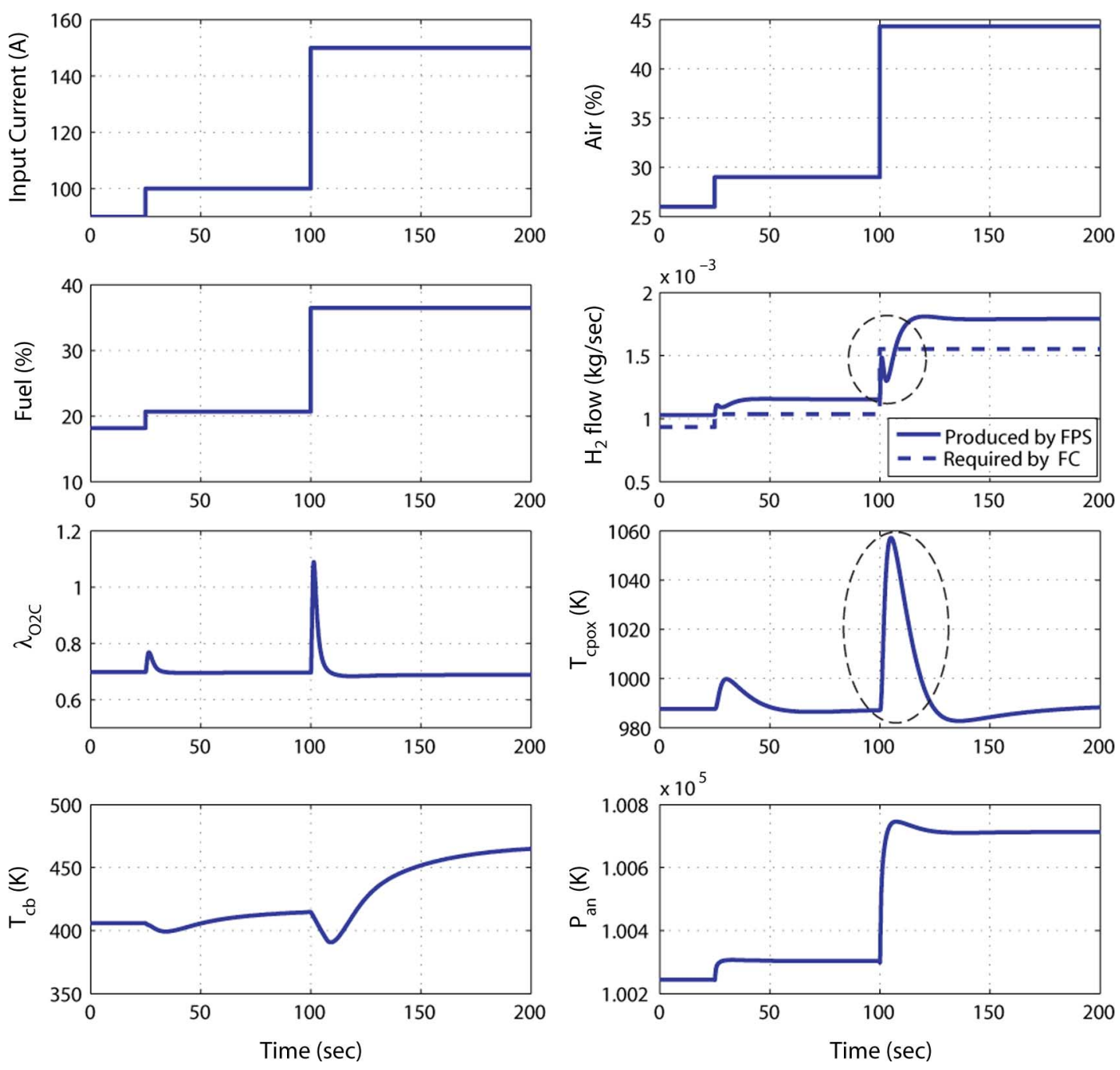

Fig. 8. Open-loop performance during 90-100-A and 100-150-A steps.
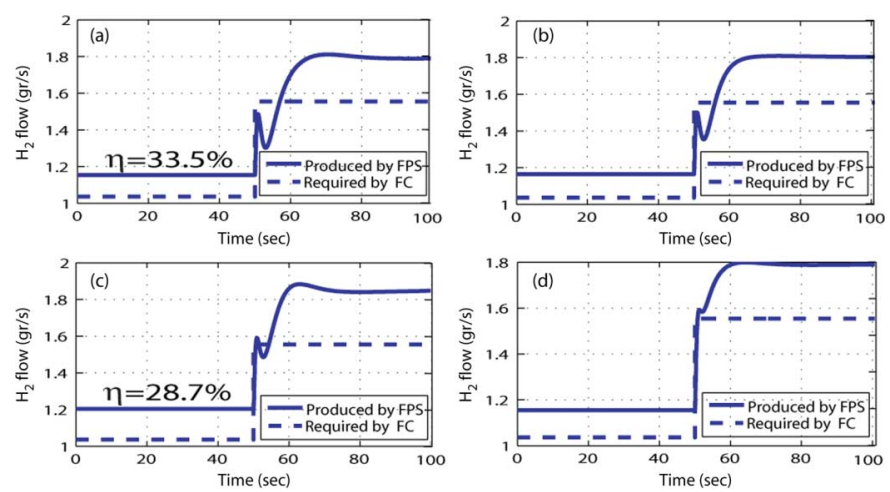

price of reduced efficiency. In the case of a suboptimal setpoint, shown in Fig. 9(c), there is an efficiency reduction from 33.5\% to $28.7 \%$ but the severity of the $\mathrm{H}_{2}$ starvation is reduced substantially.

The third and most important cause of the $\mathrm{H}_{2}$ starvation can be attributed to reactor sizing issues. The large residence time of the HDS, due to the slow kinetics of the fuel desulphurization [26], imposes the requirement of a relatively large volume compared to the adjacent volumes of the MIX and the HEX. The combination of the large volume in the fuel path, the small volume of the air path, and the large flow of air compared to the fuel flow causes the MIX pressure to build up at a rate faster than

Fig. 9. Transient performance comparison of: (a) original IHPS; (b) system with constant preheating temperature; (c) system with suboptimal maps; and (d) system with HDS volume reduced to $0.1 \mathrm{~m}^{3}$.

Furthermore, the feedforward controller, which is based on steady-state optimization, places the system close to its operating boundaries and, therefore, makes it susceptible to $\mathrm{H}_{2}$ starvation. A suboptimal map corresponds to increased excess fuel usage which implies increased $\mathrm{H}_{2}$ production in steady state. As a result, the difference between the required $\mathrm{H}_{2}$ and the produced is increased leading to increased safety margins at the the HDS pressure during transients. In turn, the pressure difference between these volumes initially exhibits an undershoot until the HDS pressure manages to build up again as illustrated in Fig. 10. Since flow is a function of the pressure difference $\left(P_{\mathrm{hds}}-P_{\mathrm{mix}}\right)$, the same undershoot is observed for the fuel flow $\left(W_{f}\right)$ which causes the oxygen-to-carbon ratio $\lambda_{O 2 C}$ to overshoot.

Based on the CPOX reaction map, given in Fig. 3, an overshoot in $\lambda_{\mathrm{O} 2 \mathrm{C}}$ from its nominal steady-state operating point of 0.69 to 1.15 , implies a steep decrease in $\mathrm{H}_{2}$ production. One way to avoid this is by decreasing the HDS volume in the model. The 

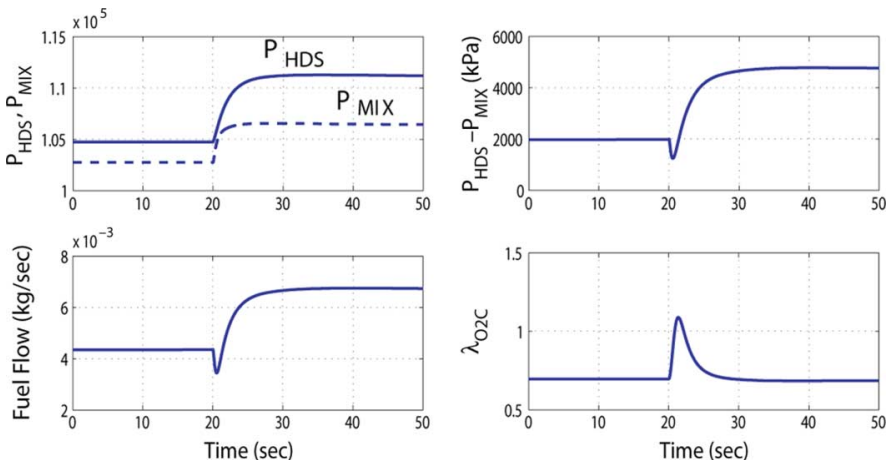

Fig. 10. $\lambda_{\mathrm{O} 2 \mathrm{C}}$ overshoot during open-loop operation.
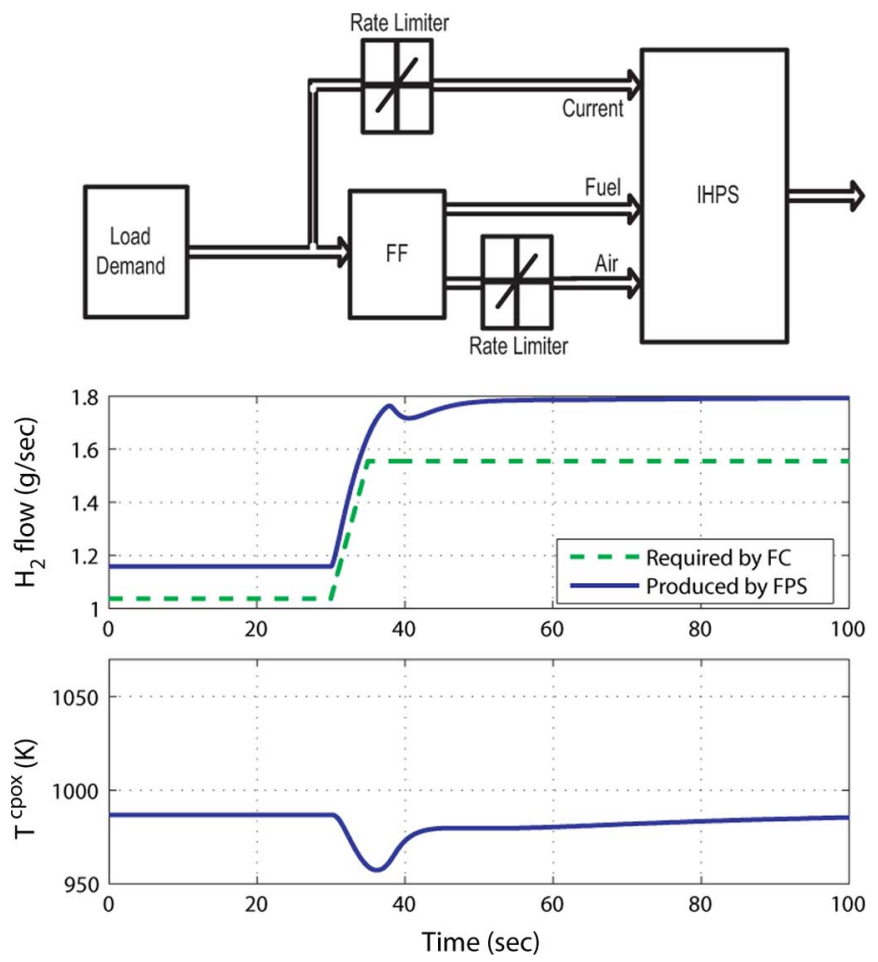

Fig. 11. System configuration and response with air rate limiter.

responses of the original system, with $V^{\text {hds }}=0.3 \mathrm{~m}^{3}$ [27], and of an imaginary system that has a considerably smaller HDS volume of $0.1 \mathrm{~m}^{3}$ are given in Fig. 9(a) and (d), respectively. For the latter case, the $\mathrm{H}_{2}$ starvation problem is significantly mitigated. If future advances in the desulphurization process produce more compact HDS reactors, then the transient performance of the system would improve. Note that recent advances in desulphurization technology allow the use of multiple smaller HDS reactors [28], [29] which would require precise switching control.

A straight forward solution to the transient problems is to apply an air rate limiter since the air flow chokes the fuel flow during transients. Such a configuration is shown in Fig. 11. A rate limiter to restrict the current drawn from the fuel cell is also required since the air rate limiter alone does not eliminate the $\mathrm{H}_{2}$ starvation problem due to the system dynamics. For a load step of 100 to $150 \mathrm{~A}$, a $2 \% / \mathrm{s}$ rate limiter and a $10 \mathrm{~A} / \mathrm{s}$ rate limiter for the air command and the current demand, respectively, are required.
Given the nonlinear dynamics of the plant, a constant rate limiter is not suitable for all load transitions. If this solution is pursed, a more elaborate load governor would be required, as presented in [3], or a scheduled filter rate, as in [30]. However, limiting the rate of load change would slow down the system response and lead to deteriorated load following performance. Rate limiters or load governors are add-on mechanisms that are applied to systems whose control capabilities have otherwise been fully explored.

\section{Feedback Control Design And Analysis}

In this section, we investigate the effectiveness of using observer-based feedback control in improving the transient performance of the IHPS. In particular, our objective is to reduce the $\mathrm{H}_{2}$ starvation problem and to control the CPOX temperature overshoot while maintaining efficient steady-state operation by utilizing the optimized feedforward maps.

The control architecture is based on setpoint error regulation, using the setpoint maps defined in Section III through the plant optimization. The controller is implemented by augmenting integrators to the estimator-based feedback controller. In deciding which signals need to be regulated and are best suited as feedback variables in the controller, one has to consider the control requirements (namely, anode $\mathrm{H}_{2}$ partial pressure and $T^{\mathrm{cpox}}$ regulation), the sensitivity of measured signals to the fuel and air actuators, as well as the ease of measuring those signals. Ideally, we would choose the CPOX temperature $T^{\mathrm{cpox}}$ and the partial pressure of $\mathrm{H}_{2}$ leaving the anode as the feedback variables, as they are linked directly to the control objectives [7]. Unfortunately, hydrogen partial pressure $P_{\mathrm{H}_{2}}$ is difficult to measure, while estimating it requires elaborate modeling of the fuel cell polarization characteristics [7], [31]. We, thus, choose the CB temperature $T^{\mathrm{cb}}$ instead. The CB temperature $T^{\mathrm{cb}}$ is closely coupled to the $\mathrm{H}_{2}$ starvation problem. During transient operation, reduction of $T^{\mathrm{cb}}$ from its optimal steady state value $T^{\mathrm{cb} *}$ implies reduction of the $\mathrm{H}_{2}$ leaving the anode exhaust and, in turn, $\mathrm{H}_{2}$ starvation. The only drawback of using $T^{\mathrm{cb}}$ instead of $P_{\mathrm{H}_{2}}$ is the slow dynamics due to the associated thermal inertia. As we show later, this drawback can be eliminated by a model-based closed-loop estimator that compensates for the slow $T^{\mathrm{cb}}$ dynamics.

The IHPS model developed can be expressed as a function of the states $x$, the inputs $u$, and the disturbance $w$ as

$$
\dot{x}=f(x, u, w)
$$

with the linear approximation of the IHPS plant being

$$
\begin{aligned}
& \delta \dot{x}=A_{p} \cdot \delta x+B_{p} \cdot \delta u+B_{w} \cdot \delta w \\
& \delta z=C_{z} \cdot \delta x
\end{aligned}
$$

where $\delta(\cdot)=(\cdot)-(\cdot)_{o}$ and $(\cdot)_{o}$ refers to the linearization setpoint. The model has 19 states (Fig. 2) and two inputs, namely the fuel and air command. The current is treated as a measured disturbance to the system. The performance variables considered are the CPOX and $\mathrm{CB}$ temperatures

$$
u=\left[\begin{array}{ll}
u_{f} & u_{a}
\end{array}\right]^{T} \quad w=I_{\mathrm{st}} \quad z=\left[T^{\mathrm{cpox}} T^{\mathrm{cb}}\right]^{T} .
$$


The medium load of $100 \mathrm{~A}$ is chosen as the linearization point. At that load, the optimization yielded steady-state fuel and air input commands of $20.75 \%$ and $29 \%$, respectively.

By looking at the eigenvalues of the linearized IHPS plant, there is a large difference between the smallest $(-0.024786)$ and the largest one $(-7062.4)$, indicating a very stiff system $\left(\operatorname{cond}\left(A_{p}\right)=8.4313 \cdot 10^{15}\right)$ with potential difficulties in tuning and assuring performance robustness. In addition, the normalized condition number of the observability gramian is very large

$$
o_{N}=\frac{\operatorname{cond}\left[Q_{\mathrm{obs},\{C=C z\}}\right]}{\operatorname{cond}\left[Q_{\mathrm{obs},\left\{C=I_{19 \times 19}\right\}}\right]}=2.5 \cdot 10^{11}
$$

where cond, $Q_{\text {obs }}$ indicate the condition number and the observability gramian, respectively.

A balanced realization [32, p. 372-376] shows that only five states are needed to describe the dynamics of the chosen performance variables. This plant will be referred to as the bt-plant and can be expressed as

$$
\begin{aligned}
\delta \dot{x}_{\mathrm{bt}} & =A_{\mathrm{bt}} \cdot \delta x_{\mathrm{bt}}+B_{\mathrm{bt}} \cdot \delta u+B_{\mathrm{wbt}} \cdot \delta w \\
\delta z & =C_{\mathrm{bt}} \delta x_{\mathrm{bt}}
\end{aligned}
$$

where $\delta x_{\mathrm{bt}}=T \delta x$. Analyzing the balanced transformation matrix $T$, we conclude that the important original states are $P^{\text {hds }}, T^{\mathrm{cb}}, T^{\mathrm{cpox}}, P_{\mathrm{H}_{2}}^{\mathrm{wrox}}$, and $m_{c}^{\text {hex }_{f}}$. This is inferred by examining the rows that correspond to relatively large Hankel singular values in the five-row transformation matrix $T$. As expected, since we want to monitor the static and dynamic behavior of $T^{\mathrm{cpox}}$ and $T^{\mathrm{cb}}$, the balanced states in turn depend on $T^{\mathrm{cpox}}$ and $T^{\mathrm{cb}}$ as well. Moreover, the transient behavior of $\mathrm{H}_{2}$ production and, thus, $T^{\mathrm{cpox}}$ and $T^{\mathrm{cb}}$ is highly coupled with $P^{\text {hds }}$ due to the transient effects analyzed earlier in Section IV. Finally, the fact that $P_{\mathrm{H}_{2}}^{\text {wrox }}$ is important can be attributed to its correlation to the $\mathrm{H}_{2}$ production from the FPS and, in turn, to the $T^{\mathrm{cpox}}$.

Checking the condition number of the observability gramian of the bt-plant we have

$$
\text { cond }\left[Q_{\mathrm{obs},\left\{C=C_{\mathrm{bt}}\right\}}^{\mathrm{bt}}\right]=34.3 \text {. }
$$

The step responses of the linear bt-plant and the nonlinear full-order plant are shown in Fig. 12. It is interesting to note that even though the dc-gain of the $u_{a}$-to- $T^{\mathrm{cb}}$ transfer function is zero, the transient dynamics are captured while for the rest, the responses of the bt and nonlinear plants are similar. Thus, as far as $T^{\mathrm{cpox}}$ and $T^{\mathrm{cb}}$ are concerned, we can conclude that no dynamic (transient) or static (dc-gain) information is lost by the truncation of the original plant.

\section{A. Controller Design}

A first approach to the controller design is the derivation of full-state feedback control which is designed using the LQR technique. The estimator design follows next. The estimator is based on the bt-plant (17) and (18) and is expressed as

$$
\delta \dot{\hat{x}}_{\mathrm{bt}}=\left(A_{\mathrm{bt}}-L \cdot C_{\mathrm{bt}}\right) \cdot \delta \hat{x}_{\mathrm{bt}}+\left[\begin{array}{lll}
L & B_{\mathrm{bt}} & B_{\mathrm{wbt}}
\end{array}\right] \cdot\left[\begin{array}{c}
\delta z \\
\delta u \\
w
\end{array}\right]
$$
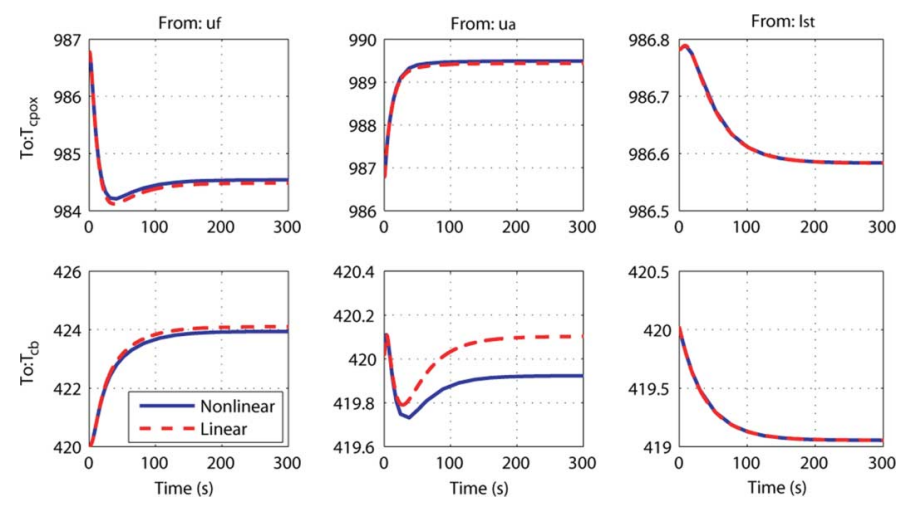

Fig. 12. Nonlinear and bt-plant response to individual $0.1 \%$ steps in $\left(u_{a}, u_{f}\right.$, $\left.I_{\text {st }}\right)$ from $(29,20.75,100)$ to $(29.29,20.96,101)$.

where the estimator gain is defined as

$$
L=S C_{\mathrm{bt}}^{T} R_{L}^{-1}
$$

and $S$ is the solution to

$$
A_{\mathrm{bt}} S+S A_{\mathrm{bt}}^{T}-S C_{\mathrm{bt}}^{T} R_{L}^{-1} C_{\mathrm{bt}} S+Q_{L}=0
$$

with process noise covariance $Q_{L}$ and the measurement noise covariance $R_{L}$

$$
Q_{L}=I_{(m \times m)}+100 \cdot B_{\mathrm{bt}} B_{\mathrm{bt}}^{T} \quad R_{L}=100 \cdot I_{(2 \times 2)} .
$$

The estimator-based linear control law is

$$
u-u_{w}=-K_{p} \cdot\left(\hat{x}_{\mathrm{bt}}-x_{\mathrm{bt}_{w}}\right)-K_{I} \cdot q
$$

where $\hat{x}_{\mathrm{bt}}=\delta \hat{x}_{\mathrm{bt}}-x_{\mathrm{bt}_{o}}$. So (24) becomes

$$
u=u_{w}-K_{p} \cdot\left(\delta \hat{x}_{\mathrm{bt}}+T\left(x_{o}-x_{w}\right)\right)-K_{I} \cdot q
$$

where $T$ is the $5 \times 19$ transformation matrix and $x_{w}$ and $u_{w}$ satisfy the steady-state condition of (12) as

$$
f\left(x_{w}, u_{w}, w\right)=0
$$

with $u_{w}$ being the optimal steady-state operating setpoint as defined by the optimization. Note that when implementing the linear control law to the nonlinear IHPS plant, the $(\cdot)_{w}$ terms are given by a feedforward map as a function of the load. At the linearization load of $100 \mathrm{~A}, x_{o}=x_{w_{\mid w=100}}$, and $x_{\mathrm{bto}}=T x_{o}$. Using (25) has several advantages over using constant setpoints. Since at steady state both $u-u_{w}$ and $x-x_{w}$ go to zero, $q$ has to go to zero as well. Thus, even if the feedforward $u_{w}$ and $x_{w}$ maps are not perfect, it will take a longer time for the integrators to become saturated. Compared to $u-u_{o}$ and $x-x_{o}$, another advantage is the initial step at the time of the load step that comes through the feedforward maps, which helps speed up the transient performance of the system.

Furthermore, in (25), $q$ are the integrator states of $T^{\mathrm{cpox}}$ and $T^{\mathrm{cb}}$ defined as

$$
\delta \dot{q}=z-z^{*}=\left[\left(T^{\mathrm{cpox}}-T^{\mathrm{cpox} *}\right)\left(T^{\mathrm{cb}}-T^{\mathrm{cb}}\right)\right]^{T}
$$




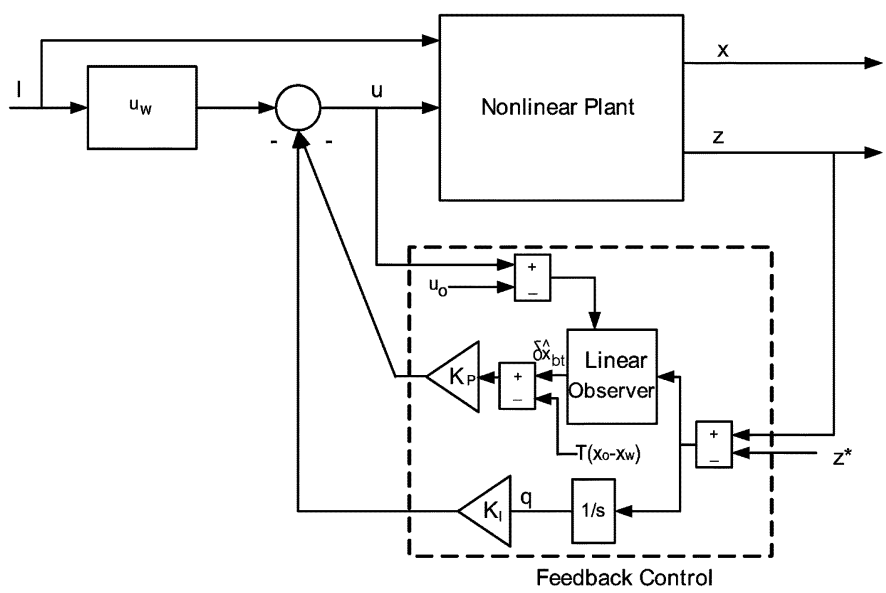

Fig. 13. Estimator-based controller applied to nonlinear plant.

where $T^{\mathrm{cpox}^{*}}$ and $T^{\mathrm{cb} *}$ are the desired steady-state points as obtained in Section III. The control gain for the augmented bt-plant (i.e., the bt-plant augmented with the two integrators) is

$$
\left[K_{p} K_{I}\right]=R_{K}^{-1} B_{\text {aug }}^{T} P
$$

and $P$ is the solution to the Riccati equation

$$
P A_{\text {aug }}+A_{\text {aug }}^{T} P-P B_{\text {aug }} R_{K}^{-1} B_{\text {aug }}^{T} P+C_{\text {aug }}^{T} Q_{K} C_{\text {aug }}=0 .
$$

The weighting matrices $Q_{K}$ and $R_{K}$ used for the controller inputs and the outputs, respectively, are

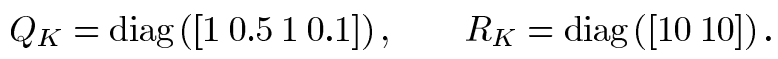

The tuning matrices for the design of $K_{p}$ and $K_{I}$ are chosen in order to achieve the desirable overshoot of the fuel and slowdown of the air command. Given the fuel actuator saturation constraints (if applicable), the gains can be tuned accordingly. The tuning gains for the design of $L$ are chosen in order to achieve the desired matching between the full-state feedback and the estimator-based controllers responses.

Finally, a schematic of the application of the estimator-based controller to the nonlinear model is given in Fig. 13.

\section{B. Performance Evaluation of the Closed-Loop System}

The feedback controller manages to improve the transient performance of the IHPS as shown in Fig. 14. It overshoots the fuel and slows down the air command initially, in order to regulate $\lambda_{\mathrm{O} 2 \mathrm{C}}$ around its optimal value and reduce the undershoot of fuel flow that is observed during open-loop operation. As a result, the $\mathrm{H}_{2}$ production increases smoothly and the $\mathrm{H}_{2}$ starvation problem is reduced.

Furthermore, the CPOX reactor temperature overshoot is substantially reduced. Application of the observer-based feedback controller yields a small overshoot which is negligible compared to the open-loop performance where $T^{\mathrm{cpox}}$ overshoots to $1060 \mathrm{~K}$ within $15 \mathrm{~s}$.

It is important to note that the performance achieved with the proposed controller, that utilizes only temperature measurements, is comparable to the performance of the controller developed in [1] for the FPS-FC system, that utilizes $T^{\mathrm{cpox}}$ and $y_{\mathrm{H}_{2}}=P_{\mathrm{H}_{2}}^{\mathrm{an}} / P^{\text {an }}$ (i.e., $\mathrm{H}_{2}$ partial pressure sensor). The latter measurement is significantly faster than $T^{\mathrm{cb}}$, since it involves pressure dynamics instead of temperature but is only available for experimental investigations. Thus, implementing a CB into an FPS, besides increasing significantly the steady-state efficiency, also provides an indirect measurement of the $\mathrm{H}_{2}$ starvation that is easy to measure and can be utilized to control the transient response.

Finally, as shown in Fig. 14, even though the $\mathrm{H}_{2}$ starvation problem is substantially alleviated compared to the open-loop case, there is still a short period of hydrogen starvation of about $0.9 \mathrm{~s}$. Obviously, the $\mathrm{H}_{2}$ production, due to the system dynamics (mainly due to the volumes involved), cannot follow the desired step response. Thus, a load rate limiter is still required to eliminate $\mathrm{H}_{2}$ starvation.

In combination with the designed estimator feedback controller, a very fast rate limiter of $40 \mathrm{~A} / \mathrm{s}$ is adequate to mitigate the $\mathrm{H}_{2}$ starvation problem completely compared a $10 \mathrm{~A} / \mathrm{s}$ limiter required for the open-loop case. Thus, with feedback control, the maximum allowable speed for load application is increased by a factor of 4 .

\section{Robustness Evaluation Against CPOX Clogging}

A well recognized problem for CPOX-FPS systems is CPOX reactor clogging due to carbon build up and deformation caused by excess temperature. Risk of CPOX clogging due to carbon formation is increased when reforming diesel or gasoline fuels, given their increased carbon concentration, but is still an issue when reforming natural gas. Deformation of the CPOX catalyst can easily occur if the CPOX temperature exceeds the meltdown temperature of the catalyst or backbone material $(1000-1100 \mathrm{~K})$, which is caused by $\lambda_{\mathrm{O} 2 \mathrm{C}}$ increase [33].

Clogging of the CPOX reactor leads to increased CPOX pressure drop. Given the low-operating pressure of the system examined in this paper, even small increase in the CPOX reactor pressure drop can increase the $\mathrm{H}_{2}$ starvation problem during a transient. In order to simulate the CPOX clogging scenario using the model developed in this paper, the CPOX outlet orifice is decreased up to $30 \%$ and the corresponding starvation period is recorded.

In Table I those results are shown for the IHPS both for the closed- and the open-loop IHPS configuration during a 100-150 A FC load step. As far as $\mathrm{H}_{2}$ starvation, it can be shown that the closed-loop control scheme exhibits satisfactory performance for up to $30 \%$ valve reduction while the open-loop scheme is not able to produce enough $\mathrm{H}_{2}$ when the valve reduction is over $8 \%$. At $30 \%$ reduction the feedback (FB) control scheme exhibits almost the same period of hydrogen starvation as the open-loop scheme exhibits at $0 \%$ orifice reduction. As far as $T^{\mathrm{cpox}}$ overshoot is concerned, the FB control scheme exhibits an acceptable value (less than 2\%) for CPOX orifice reduction up to $30 \%$. We can conclude that the robustness of the designed FB scheme is satisfactory against CPOX clogging.

\section{Robustness Evaluation Against CB Parameter Uncertainty}

Since the CB temperature is a critical measurement in the designed feedback controller, it is vital to ensure the performance 

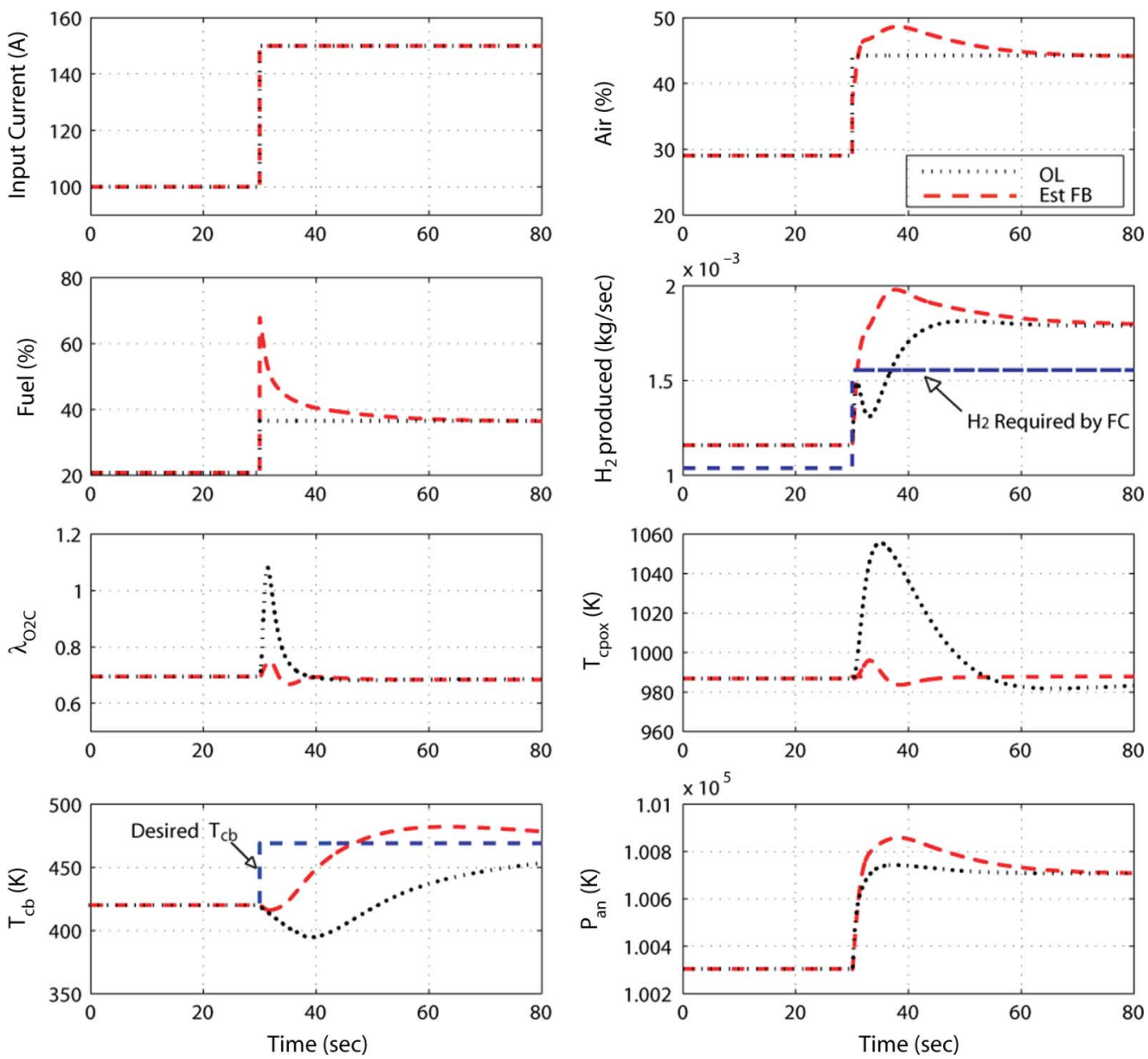

Fig. 14. Comparison of estimator FB, open-loop (OL), and state FB performance.

TABLE I

$\mathrm{H}_{2}$ STARVATION PERIOd (SP) AND $T_{\max }^{\mathrm{cpox}}$ Versus CPOX OUtLET ORIFICE SIZE REDUCTION DURING A 100-150 A LOAD STEP

\begin{tabular}{|l|l|l|l|l|}
\hline $\begin{array}{l}\text { Orifice Re- } \\
\text { duction }\end{array}$ & \multicolumn{2}{|c|}{ Closed Loop } & \multicolumn{2}{c|}{ Open Loop } \\
\hline$(\%)$ & $\begin{array}{l}\text { SP } \\
(\mathrm{sec})\end{array}$ & $\begin{array}{l}T_{\text {max }}^{\text {cpox }} \\
(\mathrm{K})\end{array}$ & SP & $\begin{array}{l}T_{\text {max }}^{\text {cpox }} \\
(\mathrm{K})\end{array}$ \\
\hline 0 & 0.9325 & 995.99 & 6.8749 & 1055.6 \\
\hline 6 & 1.1095 & 998.38 & 9.5279 & 1047.5 \\
\hline 12 & 1.5359 & 1001.2 & Inf & 1044 \\
\hline 18 & 3.4581 & 1004.5 & Inf & 1041.4 \\
\hline 24 & 4.4326 & 1008.4 & Inf & 1038.5 \\
\hline 30 & 6.1035 & 1013.2 & Inf & 1035.3 \\
\hline
\end{tabular}

robustness of the system against uncertainty of the $\mathrm{CB}$ model parameters. The dynamic response of the $\mathrm{CB}$ is mainly a function of the physical constants, namely the CB mass, $m^{\mathrm{cb}}$, and the $\mathrm{CB}$ catalyst bed heat capacity, $c_{\mathrm{Pbed}}^{\mathrm{cb}}$, which appear in the model as $\phi_{\mathrm{cb}}=m^{\mathrm{cb}} c_{\mathrm{Pbed}}^{\mathrm{cb}}$. The nominal value of $\phi_{\mathrm{cb}}$ used in the model and the observer design is based on approximate data $\left(m_{\mathrm{bed}}^{\mathrm{cb}}=10 \mathrm{~kg}, c_{\mathrm{Pbed}}^{\mathrm{cb}}=500 \mathrm{~J} / \mathrm{kg} \cdot \mathrm{K}, \phi_{\mathrm{cb}}=5000 \mathrm{~J} / \mathrm{K}[13]\right)$. Estimation though of the heat capacity and the mass can vary sig-
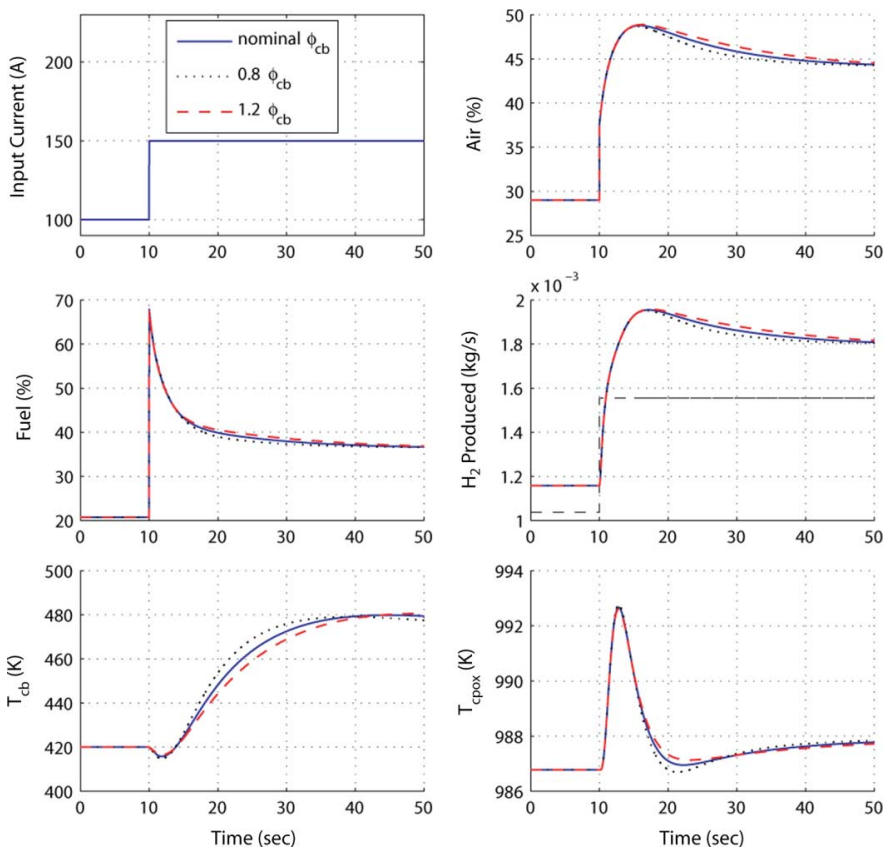

Fig. 15. Closed-loop step response with $0.8 \phi_{\mathrm{cb}}, \phi_{\mathrm{cb}}$, and $1.2 \phi_{\mathrm{cb}}$.

nificantly based on whether the catalyst, the pipes, or the shell of the reactor are taken into account. 
TABLE II

LIST OF GOVERNING EQUATIONS FOR IHPS MODEL

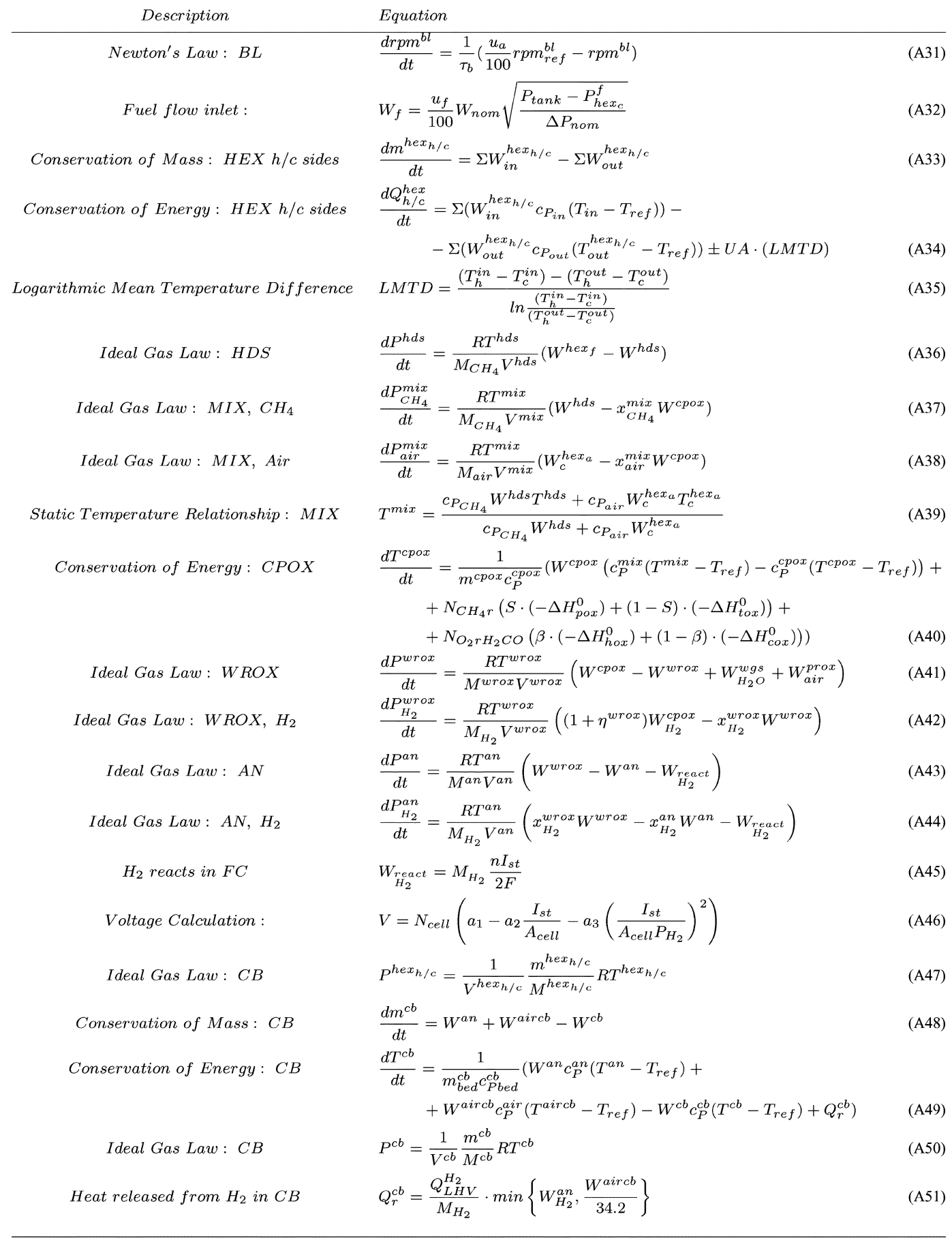

In this section, we examine whether the hydrogen production or the CPOX temperature response is affected significantly by varying $\phi_{\mathrm{cb}}$ in the plant model while keeping the same observer. Fig. 15 shows the response of the plant with $0.8 \phi_{\mathrm{cb}}, \phi_{\mathrm{cb}}$, and $1.2 \phi_{\mathrm{cb}}$ during a 100-150-A load step change with the observer-based controller designed at the nominal value $\phi_{\mathrm{cb}}$. The hydrogen starvation period and the maximum CPOX temperatures remain practically unchanged in all three cases. We can conclude that the IHPS performance does not deteriorate significantly when there is uncertainty in the $\mathrm{CB}$ parameters.

\section{CONCLUSION}

The integration of a fuel processor system with a PEM-FC and a $\mathrm{CB}$ is examined in this work. The system reforms methane to a hydrogen rich gas to be utilized in the fuel cell. The steadystate operating setpoints that yield the maximum overall efficiency of the system are determined for a wide range of FC loads. Utilizing those setpoints, the open-loop transient characteristics of the IHPS are analyzed. It is shown that the open-loop transient issues are strongly influenced by the size of the desulphurizer (HDS). The significant pressure drop of the fuel flow 
TABLE III

NOMENCLATURE DEFINITIONS

\begin{tabular}{ll}
\hline Symbol & Description \\
\hline$A_{\text {cell }}$ & Area of each cell in FC stack \\
$F$ & Farraday's Constant \\
$I_{s t}$ & FC Current \\
$M$ & Molar weight \\
$N_{\text {cell }}$ & Number of cells in FC stack \\
$P$ & Pressure \\
$Q$ & Heat \\
$Q_{L H V}$ & Lower Heating Value \\
$Q_{\text {obs }}$ & Observability gramian \\
$R$ & Gas Constant \\
$T$ & Temperature \\
$U_{H_{2}}$ & $H_{2}$ FC Utilization \\
$V$ & Volume \\
$W$ & Mass Flow \\
$\Delta H$ & Enthalpy of formation \\
$\eta$ & Efficiency \\
$c_{P}$ & Specific Heat \\
$m$ & Mass \\
$u_{a}$ & Air Setpoint \\
$u_{f}$ & Fuel Setpoint \\
$x$ & Mass fraction \\
& \\
\hline &
\end{tabular}

Sub(Super) scripts / Acronyms

$\begin{array}{ll}\mathrm{CH}_{4} \text { or } f & \text { Methane } \\ \mathrm{H}_{2} & \text { Hydrogen } \\ \mathrm{O}_{2} & \text { Oxygen } \\ * & \text { Denotes Optimal/Desired Values } \\ a & \text { Air } \\ \text { bed } & \text { Property of the reactor bed } \\ \text { in } & \text { Incoming flow Property } \\ \text { nom } & \text { Nominal Value } \\ \text { out } & \text { Outgoing flow Property } \\ r e f & \text { Reference Value } \\ & \\ F C & \text { Fuel Cell } \\ F P S & \text { Fuel Processor System } \\ \text { an } / A N & \text { Anode } \\ b l / B L & \text { Blower } \\ c b / C B & \text { Catalytic Burner } \\ \text { cpox/CPOX } & \text { Catalytic Partial Oxidizer } \\ h d s / H D S & \text { Hydro-Desulphurizer } \\ h e x h / c / H E X & \text { Heat exchanger hot/cold side } \\ \text { mix } / M I X & \text { Mixer } \\ \text { tank } & \text { Tank } \\ \text { wrox } / W R O X & \text { Water Gas Shift \& Preferential Oxidizer } \\ \end{array}$

across the HDS reactor degrades the transient performance. Due to the relatively slow dynamics along the fuel path associated with the HDS, $\lambda_{\mathrm{O} 2 \mathrm{C}}$ deviates from its steady-state value during a transient. In turn, this causes a large overshoot in the CPOX reactor temperature and an undershoot in the $\mathrm{H}_{2}$ production flow rate during open-loop operation.
Our analysis shows that implementing a CB in the FPS system does not degrade the transient performance but provides an efficiency boost of up to $16 \%$ and fuel economy of up to $12 \%$. In addition, the $\mathrm{CB}$ serves as an $\mathrm{H}_{2}$ sensor to the system. During transients the $\mathrm{CB}$ temperature variations exhibit the same trends with the $\mathrm{H}_{2}$ flow entering the $\mathrm{CB}$ and can be used as a feedback control variable. A feedback controller is designed to mitigate the transient problems identified. Using only reactor temperature measurements, namely the CPOX and CB temperatures, as inputs to the feedback controller, it is shown that satisfactory closed-loop transient performance can be achieved. Fast $\lambda_{\mathrm{O} 2 \mathrm{C}}$ regulation and a fourfold increase in $\mathrm{H}_{2}$ production rate is observed during closed-loop FC load transitions compared to the operation with the static feedforward controller.

\section{APPENDIX \\ IHPS MODEL EQUATIONS AND NOMENCLATURE}

See Tables II and III.

\section{REFERENCES}

[1] J. T. Pukrushpan, A. G. Stefanopoulou, and H. Peng, "Control of fuel cell breathing," IEEE Contr. Syst. Mag., vol. 24, no. 2, pp. 0272-1708, Apr. 2004.

[2] V. Tsourapas, J. Sun, and A. Stefanopoulou, "Modeling and dynamics of a fuel cell combined heat power system for marine applications," IASME Trans., vol. 2, no. 1, pp. 287-293, 2004.

[3] J. Sun and I. Kolmanovsky, "A robust load governor for fuel cell oxygen starvation protection," in Proc. Amer. Contr. Conf., 2004, pp. 828-833.

[4] A. Vahidi, A. Stefanopoulou, and H. Peng, "Model predictive control for starvation prevention in a hybrid fuel cell system," in Proc. Amer. Contr. Conf., 2004, pp. 834-839.

[5] V. Tsourapas, J. Sun, and A. Stefanopoulou, "Dynamics, optimization and control of a fuel cell based combined heat power (chp) system for shipboard applications," in Proc. Amer. Contr. Conf., 2005, pp. 1993-1998.

[6] J. Pukrushpan, A. Stefanopoulou, and S. Varigonda, "Control-oriented model of fuel processor for hydrogen generation in fuel cell applications," in Proc. IFAC Symp. Adv. Autom. Contr., 2004, pp. 432-437.

[7] J. T. Pukrushpan, A. Stefanopoulou, and H. Peng, Control of Fuel Cell Power Systems: Principles, Modeling, Analysis and Feedback Design, 1st ed. New York: Springer-Verlag, 2004.

[8] A. Dicks, "Hydrogen generation from natural gas for the fuel cell systems of tomorrow," J. Power Sources, vol. 61, pp. 113-124, 1996.

[9] T. Gardner, D. Berry, K. Lyons, S. Beer, and A. Freed, "Fuel processor integrated $\mathrm{H}_{2} \mathrm{~S}$ catalytic partial oxidation technology for sulfur removal in fuel cell power plants," Fuel, vol. 81, pp. 2157-2166, 2002.

[10] A. Larentis, N. de Resende, V. Salim, and J. Pinto, "Modeling and optimization of the combined carbon dioxide reforming and partial oxidation of natural gas," Appl. Catalysis, vol. 215, pp. 211-224, 2001.

[11] J. Zhu, D. Zhang, and K. King, "Reforming of $\mathrm{CH}_{4}$ by partial oxidation: thermodynamic and kinetic analyses," Fuel, vol. 80, pp. 899-905, 2001.

[12] S. Varigonda and S. A. Bortoff, "Multivariable control design for the water gas shift reactor in a fuel processor," in Proc. Amer. Contr. Conf., 2004, pp. 840-844.

[13] S. Varigonda, Communication With United Technology Research Center (UTRC). Sep. 2004.

[14] H. Jahn and W. Schroer, "Mathematical model of a residential fuel cell power plant and its application to start up optimisation," Fuel Cells Mag., vol. 4, no. 4, pp. 276-282, 2004.

[15] M. Sommer, A. Lamm, A. Docter, and D. Agar, "Modeling and dynamic simulation of a fuel cell system with an autothermal gasoline reformer," J. Power Sources, vol. 127, pp. 313-318, 2004.

[16] M. D. Lukas, K. Y. Lee, and H. Ghezel-Ayagh, "An explicit dynamic model for direct reforming carbonate fuel cell stack," IEEE Trans. Energy Convers., vol. 16, no. 3, pp. 289-295, Sep. 2001.

[17] H. K. Geyer, R. K. Ahluwalia, and R. Kumar, "Dynamic response of steam-reformed, mathanol-fueled, polymer electrolyte fuel cell systems," in Proc. 31st Intersoc. Energy Convers. Eng. Conf., 1996, pp. $1101-1106$. 
[18] W. He and K. Hemmes, "Operating characteristics of a reformer for molten carbonate fuel-cell power-generation systems," Fuel Process. Technol., vol. 67, pp. 61-78, 2001.

[19] M. Yamaguchi, T. Saito, M. Izumitani, S. Sugita, and Y. Tsutsumi, "Analysis of control characteristics using fuel cell plant simulator," IEEE Trans. Ind. Electron., vol. 37, no. 5, pp. 378-386, Oct. 1990.

[20] S. Springmann, M. Bohnet, A. Docter, A. Lamm, and G. Eigenberger, "Cold start simulations of a gasoline based fuel processor for mobile fuel cell applications," J. Power Sources, vol. 128, pp. 13-24, 2002.

[21] P. Beckhaus, A. Heinzel, J. Mathiak, and J. Roes, "Dynamics of $h_{2}$ production by steam reforming," J. Power Sources, vol. 127, pp. 294-299, 2004.

[22] R. Peters, H. Dusterwald, and B. Hohlein, "Investigation of a methanol reformer concept considering the particular impact of dynamics and long-term stability for use in a fuel-cell-powered passenger car," $J$. Power Sources, vol. 86, pp. 507-514, 2000.

[23] M. El-Sharkh, A. Rahman, M. Alam, P. Byrne, A. Sakla, and T. Thomas, "A dynamic model for a stand-alone pem fuel cell power plant for residential applications," J. Power Sources, vol. 138, pp. 199-204, 2004.

[24] P. Papalambros and D. Wilde, Principles of Optimal Design: Modeling and Computation, 2 nd ed. Cambridge, U.K.: Cambridge Univ. Press, 2000.

[25] R.-H. Song, C.-S. Kim, and D. R. Shin, "Effects of flow rate and starvation of reactant gases on the performance of phosphoric acid fuel cells," Int. J. Power Sources, vol. 86, pp. 289-293, 2000.

[26] K. Tawara and T. Nishimura, "New hydrodesulfurization catalyst for petroleum-fed fuel cell vehicles and cogenerations," Ind. Eng. Chem. Res., vol. 40, pp. 2367-2370, 2001.

[27] J. T. Pukrushpan, "Modeling and control of fuel cell systems and fuel processors," Ph.D. dissertation, Mechanical Eng. Dept., Univ. Michigan, Ann Arbor, 2003.

[28] S. K. Bej, "Revamping of diesel hydrodesulfurizers: Options available and future research needs," Fuel Process. Technol., vol. 85, pp. 1503-1517, 2004.

[29] C. Song, "An overview of new approaches to deep desulfurization for ultra-clean gasoline, diesel fuel and jet fuel," Catalysis Today, vol. 86, pp. 211-263, 2003.

[30] A. Stefanopoulou and I. Kolmanovsky, "Analysis and control of transient torque response in engines with internal exhaust gas recirculation," IEEE Trans. Contr. Syst. Technol., vol. 7, no. 5, pp. 555-566, Sep. 1999.

[31] H. Gorgun, M. Arcak, S. Varigonda, and S. Bortoff, "Observer designs for fuel processing reactors in fuel cell power systems," Int. J. Hydrogen Energy, vol. 30, pp. 447-457, 2005.

[32] J. Freudenberg, "A first graduate course in feedback control," Ph.D. dissertation, Elect. Eng. Comput. Sci. Dept., Univ. Michigan, Ann Arbor, 2002.

[33] M. Perna et al., Communication With SOFCo-EFS. May 2005.

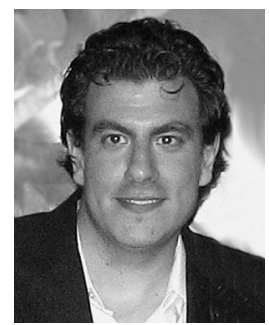

Vasilis Tsourapas (SM') received the M.S. degree in naval architecture and marine engineering from the National Technical University of Athens, Athens, Greece, in 2003 and the M.S degree in mechanical engineering from the University of Michigan, Ann Arbor, in 2005. He is currently pursuing the Ph.D. degree in the naval architecture and marine engineering department at the University of Michigan, where he is focusing on optimization and control analysis of fuel cell power systems.

Mr. Tsourapas is a recipient of the Department of Defense Graduate Fellowship and his research is partly funded by the Office of Naval Research (ONR), the National Science Foundation (NSF), the Automotive Research Center (ARC) of the University of Michigan, and the U.S. Army.

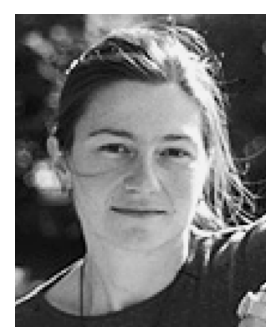

Anna G. Stefanopoulou (SM'05) received the Diploma from the National Technological University of Athens, Greece, in 1991, the M.S. degree in naval architecture and marine engineering, a second M.S. degree in electrical engineering and computer science, and the Ph.D. degree from the University of Michigan, Ann Arbor, in 1992, 1994, and 1996, respectively.

Currently, she is a Professor in the Mechanical Engineering Department at the University of Michigan. She was an Assistant Professor (1998-2000) at the University of California, Santa Barbara, and a Technical Specialist (1996-1997) at the Scientific Research Laboratories at Ford Motor Company, Dearborn, MI. Her current research interests include control of advanced internal combustion engines and fuel cell power systems.

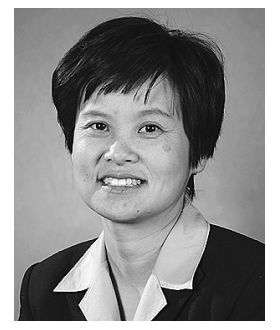

Jing Sun (F') received the Ph.D. degree from University of Southern California, Los Angeles, in 1989, and the B.S. and M.S. degrees from University of Science and Technology of China, Haifa, China, in 1982 and 1984, respectively.

From 1989 to 1993, she was an Assistant Professor in the Electrical and Computer Engineering Department, Wayne State University, Detroit, MI. She joined Ford Research Laboratory, Dearborn, MI, in 1993, where she worked in the Powertrain Control Systems Department. After spending almost 10 years in industry, she came back to academia and joined the faculty of the College of Engineering at University of Michigan in 2003 as an Associate Professor. Her research interests include system and control theory and its applications to marine and automotive propulsion systems. She holds over 30 U.S. patents and has coauthored a textbook on robust adaptive control.

Dr. Sun is one of the three recipients of the 2003 IEEE CONTROL SYSTEMS TECHNOLOGY Award. 